\title{
The Relationship Between Facebook Addiction and Depression Among Madda Walabu University Summer Students- Cross Sectional Survey
}

\author{
Mulugeta Deribe Damota \\ Madda Walabu University, College of Educational and Behavioral studies, Department of Psychology
}

\begin{abstract}
There are many studies, which have shown that Facebook addiction is a condition associated with depression. The main objective of this study is to assess the relationship between Facebook addiction and depression among Madda Walabu university summer students. 272 Purposefully selected Madda Walabu University students were the participants of the study. Cross-sectional survey design is used to assess the relationship between Facebook addiction and Depression. Facebook addiction scale and Burns depression checklist are used to collect pertinent data. The study revealed a positive significant relationship between Facebook addiction and depression. The research recommends Madda Walabu University should develop education programs and special plans to deal with Facebook addiction to saving its students from Depression.
\end{abstract}

Keywords: Addiction, Depression, Facebook

DOI: $10.7176 / \mathrm{NMMC} / 78-01$

\section{Introduction}

Social media site is web-based systems that help persons to connect in an electronic way with others of the same interests and to make their connections to public persons. Studies indicated that about two-thirds of adults using the internet are on social media (Kittinger et al., 2012). Facebook is one of the most widely used social media sites and it provides people the ability to share news, thoughts, photos, and video and make the world more open and connected (Masthi et al., 2015) and this makes it very popular to university students(Alexander,2006; Lin et al., 2012); Koc \& Gulyagci, 2013).

This new method of communication find high acceptance among students (Masthi et al.,2015) and become a public domain in 2006 (Boyd \& Ellison,2007). Facebook become more popular and in 2007, reach more than 21 million active users and generating 1.6 billion page views each day (Boyd \& Ellison,2007).

A study in 2011, show that half to two-thirds of teenagers and young adults use Facebook on regular basis (Kuss \& Griffiths, 2014. Facebook addiction is similar to habitual patterns of behavior associated with activities like gambling, shopping and Internet addiction (Zeinab et al.,2014). Use Facebook in an excessive way has been found to harm psychological and social well-being of individuals and their personality, for example, Alabi(2013) found that the personal life is truly affected when the person was an addict on Facebook as a result of uncontrolled behavior regarding Facebook using.

Depression is understood and known as an internalizing problem in people which is classified by its symptoms like, depressed mood or excessive sadness, loss of interest in activities, sleeping problems, difficulty in thinking, and loss of concentration (Merrell, 2008,) Depression normally change mood to the length of severity, $10 \%$ or less than $10 \%$ of the population at a certain point in time, suffers from psychiatric or psychosocial problem that needs intervention (WHO 2007.) Although the benefits and advantages of social networking sites like Facebook are noted, problems caused by heavy usage of social networking sites are not forgotten. According to Isbulan (2011) today almost all people prefer to communicate with their friends and social environment by using social networking sites instead of face to face communication. This process can turn into addiction after a while and it makes the user spend more and more time on Facebook.

The increase of psychological and addiction problems caused heavy usage of Facebook leads to educationalists and psychiatrists to worry about negative effects of Facebook on public health. According to Harzadın (2012), Facebook addicts have a problem with their families, friends, jobs, school environments, start to remain at home almost all day, be too passive to the events which occur in their environment when they are in front of the Facebook screen.

There are many studies, which have shown that Internet addiction is a condition associated with psychiatric disorders, such as affective disorders, anxiety disorders and attention deficit hyperactivity disorder (ADHD). For example, $78 \%$ of German students who had internet addiction disorder had major depressive disorders, and a correlation was found amongst Internet addiction, depression and thoughts of suicide in South Korean adolescents (Weinstein \& Lejoyeux, 2010).

A study conducted by (Nitt et al., 2015) indicated The Facebook addiction group had higher general mental health problems than the normal group whereas the severe Facebook addiction group was at the highest risk of abnormal mental health. A study conducted by Rabadi et al., (2017) shown significant correlations between 
internet addiction and depression: Internet addiction-related positively to depression. Another study conducted by Walker (2014), identified there is a likelihood that heavy Facebook use can steer to mental illnesses such as depression. People being addicted to Facebook use it daily and compare their life with those of others known as "social comparison", if it's an upward comparison it tends to make people feel more then worse due to which they may start living aloof. This notion is also supported by Moreno (2012) suggested a positive correlation between Facebook use and depression

A report Africa 2018 population and internet users' statistics indicated, there are large numbers of Facebook subscribers in 2017 in Ethiopia compared with the report of 2000 as indicated below.

Table 1: internet users' statistics in Ethiopia

\begin{tabular}{|c|c|c|c|c|c|c|}
\hline Country & $\begin{array}{l}\text { Population } \\
\text { (2018 Est.) }\end{array}$ & $\begin{array}{l}\text { Internet } \\
\text { Users } \\
\text { 31-Dec-2000 }\end{array}$ & $\begin{array}{l}\text { Internet } \\
\text { Users } \\
\text { 31-Dec-2017 }\end{array}$ & $\begin{array}{l}\text { Penetration } \\
(\% \\
\text { Population })\end{array}$ & $\begin{array}{l}\text { Internet } \\
\text { Growth \% } \\
2000-2017\end{array}$ & $\begin{array}{l}\text { Facebook } \\
\text { subscribers } \\
\text { 31-Dec-2017 }\end{array}$ \\
\hline Ethiopia & $107,534,882$ & 10,000 & $16,437,811$ & $15.3 \%$ & $164,278 \%$ & $4,500,000$ \\
\hline
\end{tabular}

In Ethiopian, government and self-sponsored students attend their education during the summer program for two consecutive months up to six consecutive summer program to be graduated. These students are expected to master the courses allocated for each summer program based on their department's curriculum. Within this short period of time, if students do not properly use their time and devote a high amount of time on Facebook, they might be frustrated from achieving their intended goal.

In Ethiopia, there have not been any relevant studies about the psychological impacts of Facebook usage among students. This study conducted on the students of Madda Walabu University, Oromia, Ethiopia, aims to determine Facebook addiction and depression among Madda Walabu university summer program students. In addition to this, the study also aims to show the magnitude of both Facebook addiction and depression among selected Facebook users.

\section{Research questions}

1. What are the Facebook addiction levels of participants?

2. What is the prevalence rate of depression among summer students?

3. Is there any significant relationship between Facebook addiction and depression?

\section{Method and Materials}

\section{Description of the study area}

The study was conducted in Madda Walabu University students who are attending their first-degree program during summer. Madda Walabu University was established in 2006 in Bale Zone, Oromia, about 430 kilometers South East of the capital city of Ethiopia. In 2018, the University has three campuses: Robe campus Goba and Shashemene campus. Robe campus is the main campus of the University, which is found in Robe town in which this study was conducted.

\section{Research design}

In order to assess the correlates and prevalence of psychological distress among Madda Walabu University students who were attending their education during the summer season, the cross-sectional research design was employed

\section{Participants}

272 purposefully selected summer program students were included in this study from different departments.

\section{Measures}

To identify the level of depression among students, Burn's Depression Checklist which is Likert scale ranges 0-4 was employed. The Burns Depression Checklist (BDC) is a highly regarded rating scale for depression developed by David Burns, MD (Morgan 2016). The scale/checklist consists of 25 items and the respondents were asked to indicate how much they have experienced each symptom during the past week, including that moment.

\begin{tabular}{l|l}
\hline Total Score & Level of Depression \\
\hline $0---5$ & No Depression \\
\hline $6---10$ & Normal but unhappy \\
\hline $11---25$ & Mild depression \\
\hline $26---50$ & Moderate depression \\
\hline $51---75$ & Severe depression \\
\hline $76---100$ & Extreme depression \\
\hline
\end{tabular}


For Facebook addiction, 29 items which are True/False Facebook addiction scale was used to identify the magnitude of Facebook addiction among respondents.

\section{Ethical Consideration}

A letter introducing the objective of the study, and maintaining the confidentiality was attached as the cover page of the questionnaire. Participants gave oral consent for participating in the study. If the respondent is not a volunteer, the right to refuse will be clearly stated in the letter to participate in the study.

\section{Result}

Demographic Data of Respondents

Table 2: gender of participants * age of students Cross tabulation

Count

\begin{tabular}{ll|r|r|r|r|r}
\hline & & \multicolumn{2}{|c|}{ age of students } & \multirow{2}{*}{ Total } & $\%$ \\
\cline { 3 - 6 } & & $20-30$ & $31-40$ & $>40$ & & \\
\hline \multirow{2}{*}{ gender of participants } & male & 153 & 42 & 3 & 198 & 72.8 \\
\multirow{2}{*}{ Total } & female & 55 & 19 & 0 & 74 & 27.2 \\
\hline
\end{tabular}

As indicated above in Table 2, most of the respondents $(198(72.8)$ are males and the rest $72(27.2 \%)$ are females. With respect to their age, 153 male students are under the interval of 20-30, 42 of them from 31-40 and 3 students are above 40 . On the other hand, 55 female students are found under the age interval of 20-30, and the rest 18 students were from $31-40$.

Prevalence of Depression and Facebook addiction

Table 3: The magnitude of Depression

\begin{tabular}{l|l|r|r|c}
\hline & \multicolumn{1}{|c|}{ Frequency } & Percent & Valid Percent & Cumulative percent \\
\hline No depression & 19 & 7.0 & 7.0 & 7.0 \\
\hline Normal but unhappy & 21 & 7.7 & 7.7 & 14.7 \\
\hline Mild & 97 & 35.7 & 35.7 & 50.4 \\
\hline Moderate & 100 & 36.8 & 36.8 & 87.1 \\
\hline Severe & 32 & 11.8 & 11.8 & 98.9 \\
\hline Extremely severe & 3 & 1.1 & 1.1 & 100.0 \\
\hline Total & 272 & 100.0 & 100.0 & \\
\hline
\end{tabular}

The above table 3 indicated the magnitude of depression among summer students. Most of the students $232(85.3 \%)$ are found under depressive symptoms. Specifically, 97(35.7\%) mild, 100(36.8\%) moderate, $32(11.8 \%)$ severe and $3(1.1 \%)$ extremely severe.

The magnitude of Facebook Addiction

Table 4: Facebook addiction level

\begin{tabular}{ll|r|r|r}
\hline & Frequency & Percent & Valid Percent & Cumulative Percent \\
\hline light user & 20 & 7.4 & 7.4 & 7.4 \\
part of their life routine & 53 & 19.5 & 19.5 & 26.8 \\
Valid & 143 & 52.6 & 52.6 & 79.4 \\
obsessive/unhealthy user & 56 & 20.6 & 20.6 & 100.0 \\
their lives revolve around facebook & 272 & 100.0 & 100.0 & \\
Total &
\end{tabular}

The above table 4 depicted the rate of Facebook addiction among summer students at Madda Walabu University. As shown above, from the respondents 20(7.4\%) light Facebook users, for 53(19.5\%), Facebook is part of their lives routine and 143(52.6\%) of students are obsessive or unhealthy Facebook users. The rest $56(20.6 \%)$ of students live to revolve around Facebook. 
Table 5: Cross Tabulation between depression and Facebook addiction

\begin{tabular}{|c|c|c|c|c|c|c|}
\hline & \multicolumn{4}{|c|}{ Facebook addiction } & \multirow[t]{2}{*}{ Total } \\
\hline & & $\begin{array}{l}\text { light } \\
\text { user }\end{array}$ & $\begin{array}{l}\text { part of their life } \\
\text { routine }\end{array}$ & $\begin{array}{c}\text { obsessive/unhealthy } \\
\text { user }\end{array}$ & $\begin{array}{l}\text { their lives revolve } \\
\text { around Facebook }\end{array}$ & \\
\hline \multirow{6}{*}{ depression } & no depression & 3 & 8 & 7 & 1 & 19 \\
\hline & $\begin{array}{l}\text { normal but } \\
\text { unhappy }\end{array}$ & 4 & 3 & 11 & 3 & 21 \\
\hline & mild & 6 & 18 & 55 & 18 & 97 \\
\hline & moderate & 4 & 17 & 55 & 24 & 100 \\
\hline & severe & 3 & 6 & 13 & 10 & 32 \\
\hline & $\begin{array}{l}\text { extremely } \\
\text { severe }\end{array}$ & 0 & 1 & 2 & 0 & 3 \\
\hline Total & & 20 & 53 & 143 & 56 & 272 \\
\hline
\end{tabular}

The above table 5 disclosed the cross-tabulation of Facebook addiction and depression. As shown above, most of the respondents are found under moderate depression and obsessive or unhealthy Facebook utilization. Table 6: Pearson correlations between Facebook addiction and depression

\begin{tabular}{ll|r|r}
\hline & & Facebook Addiction & Depression \\
\hline \multirow{3}{*}{ Facebook Addiction } & Pearson Correlation & 1 & $.192^{* *}$ \\
& Sig. (2-tailed) & & .001 \\
& $\mathrm{~N}$ & 272 & 272 \\
depression & Pearson Correlation & $.192^{* *}$ & .001 \\
& Sig. (2-tailed) & 272 & 1 \\
& $\mathrm{~N}$ & 272 \\
\hline
\end{tabular}

**. Correlation is significant at the 0.01 level (2-tailed).

As indicated above Table 6: there is a positive significant relationship between Facebook addiction and depression. But the degree of relationship is considered as weak.

\section{Discussion}

Concerning the prevalence of Facebook addiction among students the study revealed most the respondents were problematic internet users. The study is consistent with the study conducted in In Pakistan revealed that multiple signs of Facebook addiction were present in medical students (Farooqi et al., 2013). In contrary, only 8\% of participants reported high Facebook use/addiction. Here it is noteworthy that the participants were permitted to use other social networking sites in addition to Facebook. Oluwole Folaranmi (2013) observed the low levels of Facebook addiction among selected Nigerian undergraduates which was $1.6 \%$.

The result revealed that there was a positive significant relationship between Facebook addiction \& depression. Tokunaga and Rains (2010) found a similar positive significant relationship between depression and problematic Internet use. In line with this, Zaffar et al., 2015 study showed that the positive correlation between Facebook Addiction and Depression. The study also shows that there is a significant relationship between Facebook Addiction and Depression. Users with Facebook addiction were also found to have an increased risk of depressive symptoms (Hanprathet et al., 2015). In another study, college students with depressive symptoms were more likely to use Facebook excessively (Koc et al., 2013). Walker (2014), research also identified there is a likelihood that heavy Facebook use can steer to mental illnesses such as depression. There are also other similar studies identified the significant relationship (Nitt et al., 2015); Rabadi et al., (2017); Moreno (2012). These studies identified a positive correlation between Facebook use and depression.

There is also an incongruent study conducted by Błachnio et al. (2015). Their study result showed there was no statistical significance between total time spent and depressive symptoms (Błachnio et al., 2015). In line with this, Chen et al. (2013) also found a similar indirect effect between Facebook interactions and psychological distress. Jelenchick et al.,(2013); Farooqi et al., (2013) results found no significant association between Facebook use and depression.

The difference found in this study is attributed to three basic factors. Hierarchically, instruments difference, samples, and design of the studies.

\section{Conclusions}

A very high number of students were observed as problematic Facebook users and developed depressive symptoms. This may result in a problem with their families, friends, jobs, school environments.

There is a statistically positive significant relationship between Facebook addiction and depression even if 
the degree of the relationship was weak. Increase in spending more time on Facebook may increase and develop depressive symptoms

\section{The way forward}

In Ethiopia, generally, the influence of Facebook is not sufficiently studied. It is becoming a serious problem among students unless due consideration is given, it may provide serious mental problem among students. From the context of this study, Madda Walabu University should develop education programs and special plans to deal with Facebook addiction to saving the generation which is becoming the generation of the online social world.

A very deep investigation is needed to clearly identify the magnitude of social media especially Facebook utilization among students by including more samples and very well organized instruments.

\section{Acknowledgments}

I would like to appreciate Madda Walabu University Students for their volunteer participation and staffs (Kefale Seifu and Essa Aliye) for their support in editing the translated instrument

I would like to thank my wife Senait Degafa for her translation the instrument to Afan Oromo Language

\section{Conflict of interest}

I declare there is no conflict of interest with other Authors and I assure that I am responsible for any conflict of interest that may arise.

\section{References}

Kittinger R, Correia CJ \& Irons JG. The relationship between Facebook use and problematic internet use among college students. CyberPsychology, Behavior and Social Networking 2012; 15(6),324.

Masthi R Ramesh, Shreyas R Cadabam, Sonakshi S. Facebook addiction among health university students in Bengaluru. International Journal of Health \& Allied Sciences Jan-Mar 2015; Vol. 4(1), 18-22.

Alexander B. A new wave of innovation for teaching and learning? Educause review 2006; 41(2), 32.

Lin Y, Le N, Cheng K. Social media usage and work values: The Example of Facebook in Taiwan. Soc Behav Pers 2012; 40:195 200.

Koc M \& Gulyagci S. Facebook addiction among Turkish college students: The Role of Psychological Health, Demographic, and Usage Characteristics. Cyberpsychology Behavior and Social Networking, 2013; 16(4):279-84.

Boyd M \& Ellison B. Social network sites: Definition, history, and scholarship. Journal of Computer-mediated Communication 2007; 13(1)210-230.

Kuss J \& Griffiths D. Addiction to social networks on the internet: A literature review of Empirical researches. International Journal of mental health and addiction 2012; Vol. 10(2): 278-296.

Zeinab Z, Abu B, Zobidah S, Bolong J \& Akhtar K. Addictive Facebook Use among University Students. Asian Social Science 2014; $10(6): 107-116$.

Folaranmi.O A Survey of Facebook Addiction Level among Selected Nigerian University Undergraduates. New Media and Mass Communication. 2013; Vol.10:70-80.

Merrell, K. W. 2008. Helping Students Overcome Depression and Anxiety. 2nd Edition. 72 spring street New York.

World Health Organisation. 2007. Mental Health and Substance abuse. Available: http://www.searo.who.int/en/section1174/section1199/section1567_6741.htm Accessed 7 September 2011.

İsulan O. (2011), Opinions of University Graduates about Social Networks According to Their Personal Characteristics. Turkish Online Journal of Educational Technology, 10 (2): 184-189.

Hardazin, T. (2012), Facebook Bağımlılığı.http://www.psikolojikterapi.com/facebook-bagimliligi.html, (Erişim: 13 Nisan 2012).

Weinstein A, Lejoyeux M. Internet addiction or excessive internet use. Am J Drug Alcohol Abuse 2010; 36 ; 277-83.

Nitt H, Mereerat M, Jiraporn K, Rungmanee Y, Muthita Ph, FPCPsychT, Facebook Addiction and Its Relationship with Mental Health among Thai High School Students(2015) Journal of the Medical Association of Thailand Chotmaihet Thangphaet · May 2015

Rabadi L, Ajlouni M, Masannat S, Bataineh S, Batarseh G, et al. (2017) The Relationship between Depression and Internet Addiction among University Students in Jordan. J Addict Res Ther 8: 349. doi:10.4172/21556105.1000349

Walker, L. (2014). Facebook addiction definition: Facebook addicts spend excessive time on Facebook. [Online] Retrieved from: http://personalweb.about.com/od/facebookculture/g/face book-addiction-definition.htm [Accessed: 9 April 2015].

Moreno A, Christakis A, Egan G, et al: A pilot evaluation of associations between displayed depression 
references on Facebook and self-reported depression using a clinical scale. J Behav Health Serv Res 2012; 39:295-304

Farooqi, H, Patel, H. Aslam, H., Ansari I., Khan, M., \& Iqbal, N. et al. Effect of Facebook on the life

of Medical University students. International Archives of Medicine, 6(1), 40 (2013).

Folaranmi, O. A Survey of Facebook Addiction Level among Selected Nigerian University Undergraduates. New Media and Mass Communication, 10. (2013).

Tokunaga, R. S., \& Rains, S. A. An evaluation of two characterizations of the relationships betweenproblematic internet use, time spent using the internet, and psychosocial problems. Human Communication Research, 36(4), 512- 545 (2010).

Zaffar. M, Shazara Mahmood, Muhammad Saleem Ezarina Zakaria Sci.Int. Facebook Addiction: Relation With Depression, Anxiety, Loneliness And Academic Performance Of Pakistani Students (Lahore),27(3),24692475,2015

Hanprathet N, Manwong M, Khumsri J, et al Facebook addiction and its relationship with mental health among Thai high school students. J Med Assoc Thail Chotmaihet thangphaet 2015; 98: $\quad$ S81-S90

Koc M, Gulyagci S: Facebook addiction among Turkish college students: the role of psychological health, demographic, and usage characteristics. CyberPsychology Behav Soc Netw 2013; 16:279-284

Błachnio A, Przepiórka A, Pantic I: Internet use, Facebook intrusion, and depression: results of a cross-sectional study. Eur Psychiatry J Assoc Eur Psychiatr 2015; 30:681-684 16.

Chen W, Lee K-H: Sharing, liking, commenting, and distressed? the pathway between Facebook interaction and psychological distress. CyberPsychology Behav Soc Netw 2013; 16:728-734

Jelenchick LA, Eickhoff JC, Moreno MA: "Facebook depression?" social networking site use and depression in older adolescents. J Adolesc Health 2013; 52:128-130 